Atmos. Chem. Phys., 19, 15583-15586, 2019

https://doi.org/10.5194/acp-19-15583-2019

(C) Author(s) 2019. This work is distributed under

the Creative Commons Attribution 4.0 License.

\title{
Technical note: A simple method for retrieval of dust aerosol optical depth with polarized reflectance over oceans
}

\author{
Wenbo Sun ${ }^{1,3}$, Yongxiang Hu${ }^{2}$, Rosemary R. Baize ${ }^{2}$, Gorden Videen ${ }^{3,4}$, Sungsoo S. Kim ${ }^{3}$, Young-Jun Choi ${ }^{5}$, \\ Kyungin Kang ${ }^{6}$, Chae Kyung $\mathrm{Sim}^{3}$, Minsup Jeong ${ }^{5}$, Ali Omar ${ }^{2}$, Snorre A. Stamnes ${ }^{2}$, David G. MacDonnell ${ }^{2}$, and \\ Evgenij Zubko ${ }^{3}$ \\ ${ }^{1}$ Science Systems and Applications Inc, Hampton, Virginia 23666, USA \\ ${ }^{2}$ NASA Langley Research Center, Hampton, Virginia 23681, USA \\ ${ }^{3}$ Kyung Hee University, Yongin-shi, Kyungki-do 17104, Korea \\ ${ }^{4}$ US Army Research Lab, Adelphi, Maryland 20783, USA \\ ${ }^{5}$ Korea Astronomy and Space Science Institute, Yuseong-gu, Daejeon 34055, Korea \\ ${ }^{6}$ Korea Advanced Institute of Science and Technology, Daejeon 34141, Korea
}

Correspondence: Wenbo Sun (wenbo.sun-1@ nasa.gov)

Received: 9 August 2019 - Discussion started: 21 August 2019

Revised: 18 November 2019 - Accepted: 28 November 2019 - Published: 19 December 2019

\begin{abstract}
Our previous study shows that the angle of linear polarization (AOLP) of solar radiation that is scattered from clouds at near-backscatter angles can be used to detect super-thin cirrus clouds over oceans. Such clouds are too thin to be sensed using any current passive satellite instruments that only measure light's total intensity, because of the uncertainty in surface reflection. In this report, we show that with a method similar to the super-thin cloud detection algorithm, dust aerosols may also be detected and differentiated from clouds. We also show that the degree of polarization of reflected light can be used for retrieving the optical depth of dust aerosols in the neighborhood of the backscatter angle, regardless of the reflecting surface conditions. This is a simple and robust algorithm, which could be used to survey dust aerosols over midlatitude and tropical oceans.
\end{abstract}

A NASA-Korea CubeSat mission is currently under preparation by NASA Langley Research Center, the Korea Astronomy and Space Science Institute (KASI), and Kyung Hee University of Korea. We plan to use polarimeters on two CubeSats to detect the super-thin clouds over global oceans and dust aerosols over oceans and land around the Korean Peninsula. The polarimeters will be developed by KASI and are modified versions of the Polarimetric Camera (PolCam) developed by KASI for the Korea Pathfinder Lunar Orbiter (KPLO). This planned polarimeter-on-CubeSat mission will measure the polarization features of scattered light from clouds and aerosols to identify the super-thin clouds and dust aerosols over oceans and retrieve their optical depth.

Our previous works (Sun et al., 2014, 2015) show that distinct features exist in the angle of linear polarization (AOLP) of solar radiation that is scattered from clouds at nearbackscatter angles. At these angles the dominant electric field from clear-sky oceans is nearly parallel to the Earth's surface. However, when clouds are present, this electric field can rotate significantly away from the parallel direction. Our modeling results suggest that this polarization feature can be used to detect super-thin cirrus clouds with an optical depth of only $\sim 0.06$ and super-thin liquid water clouds with an optical depth of only $\sim 0.01$. Such clouds are too thin to be sensed using any current passive satellite instruments that 
only measure light's total intensity, because of the uncertainty in surface reflection.

Similarly to super-thin clouds, aerosols such as dust particles also affect surface remote sensing and global climate significantly. The optically thin aerosols are also very difficult to detect even over a dark surface condition such as oceans. In optical remote sensing of aerosols, how to distinguish between surface and atmospheric contributions to the TOA reflectance remains a problem. Because of aerosols' small optical thickness, the uncertain effect of ocean surface reflection on the light cannot be well quantified when using total reflectance as a measurement to the aerosols, even with multiple angles and wavelengths in measurements (Dubovik et al., 2019). Several methods are proposed to separate the atmospheric and surface contributions (e.g., Kaufman et al., 1997), but no ideal method has been reported to date. The use of the degree of polarization of the radiance is thought to have great potential for aerosol retrieval (Herman et al., 1997). However, the retrieval method of remote sensing of aerosols based on polarized radiation measurement is still in progress (Dubovik et al., 2019). Based on our modeling results, we will propose a novel method of using passive polarimetric instruments to detect dust aerosols over oceans in this paper.

Unpolarized solar radiation can be polarized by surface reflections as well as by scattering from atmospheric molecules and particles. When sunlight propagates through a clear atmosphere and is scattered back toward the Sun, the resulting signal is nearly unpolarized when the solar zenith angle (SZA) is less than $\sim 40^{\circ}$ (Sun and Lukashin, 2013). By considering a longer solar wavelength, such as $670 \mathrm{~nm}$, the contribution of molecular scattering is small. Unlike total radiance $(I)$, the degree of polarization (DOP) and angle of linear polarization (AOLP) of the reflected sunlight are insensitive to surface roughness and absorption by atmospheric water vapor and other gases (Sun and Lukashin, 2013). This insensitivity makes the polarization measurement robust for different environmental conditions, even when the detected components are within the lower layers of the atmosphere. For example, super-thin water clouds close to the surface of the Earth that cannot be detected using $1.38 \mu \mathrm{m}$ radiance can be identified by the polarization properties of light backscattered from them. The method for using the AOLP feature to detect super-thin clouds is reported in Sun et al. (2014). The method for using polarized reflectance to retrieve the optical depth of super-thin clouds is reported in Sun et al. (2015). Sun et al. (2015) report that the optical depth of super-thin clouds can be retrieved at near-backscatter angles without the effect of background reflection.

Our studies show that the polarization of backscattered light can also be applied to aerosol remote sensing. Figure 1 shows the modeled DOP of reflected sunlight at $670 \mathrm{~nm}$ from dust aerosols over oceans. Also shown in this figure are results from $12 \mathrm{~d}$ of PARASOL level-1 reflectance and level-2 ocean aerosol and cloud data (Deschamps et al., 1994; Buriez

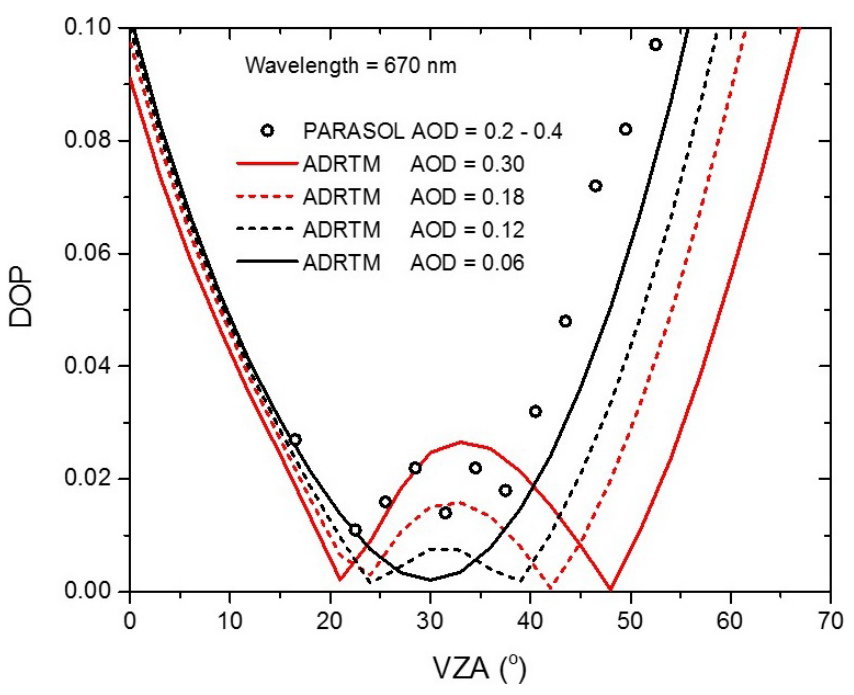

Figure 1. At near-backscatter angles (for this case, it is at viewing zenith angle $(\mathrm{VZA})=\sim 20-40^{\circ}$ and relative azimuth angle $\left.(\mathrm{RAZ})=\sim 170-180^{\circ}\right)$, the DOP of light from dust monotonically increases with the AOD of dust aerosols. In this modeling, the adding-doubling radiative transfer model (ADRTM) developed in Sun and Lukashin (2013) is used. The wavelength is $670 \mathrm{~nm}$, the solar zenith angle (SZA) is $30^{\circ}$, and the wind speed over the ocean surface is $7.5 \mathrm{~m} \mathrm{~s}^{-1}$. Also shown in this figure are the PARASOL measurements obtained over the Atlantic Ocean area $\left(0-35^{\circ} \mathrm{N}\right.$ and $0-60^{\circ} \mathrm{W}$ ) that has Sahara dust; $12 \mathrm{~d}$ of PARASOL data in MayAugust 2006 are used for this study. The results are for a RAZ of $177^{\circ}$.

et al., 1997; Tanré et al., 2011) across May to August 2006. In the modeling, we assume the dust particles are nonspherical debris aggregates with a refractive index of $1.4+0.01 i$ (Zubko et al., 2006, 2009, 2013). The aerosols are within a $1 \mathrm{~km}$ layer over the ocean surface. The aerosol size distribution and single-scattering property calculation follow those reported in Sun and Lukashin (2013). The PARASOL measurements obtained over the Atlantic Ocean area $\left(0-35^{\circ} \mathrm{N}\right.$ and $0-60^{\circ} \mathrm{W}$ ) are used to capture Sahara dust over oceans. Only those data with an AOD $=0.2-0.4$ from the PARASOL OC2 dataset are used for comparison with the modeled results. We can see that the modeled DOP of reflected light is a strong function of dust AOD. At the near-backscatter viewing angles, the DOP of reflected light monotonically increases with the AOD. This means that when using a polarimeter at these observation angles, AOD can be retrieved from the DOP of the backscattered light. The PARASOL data well prove the modeled results at the near-backscatter angles. However, significant difference is found at other viewing angles, with unknown reasons. Figure 2 shows the AOLP of the reflected light from the ADRTM (left panel, $\mathrm{AOD}=0.3$ ) and the PARASOL (right panel, AOD $=0.2-0.4$ ). We can see that at near-backscatter angles, AOLPs from the model and satellite data are significantly different. The PARASOL results have a glory pattern at near-backscatter angles that in- 

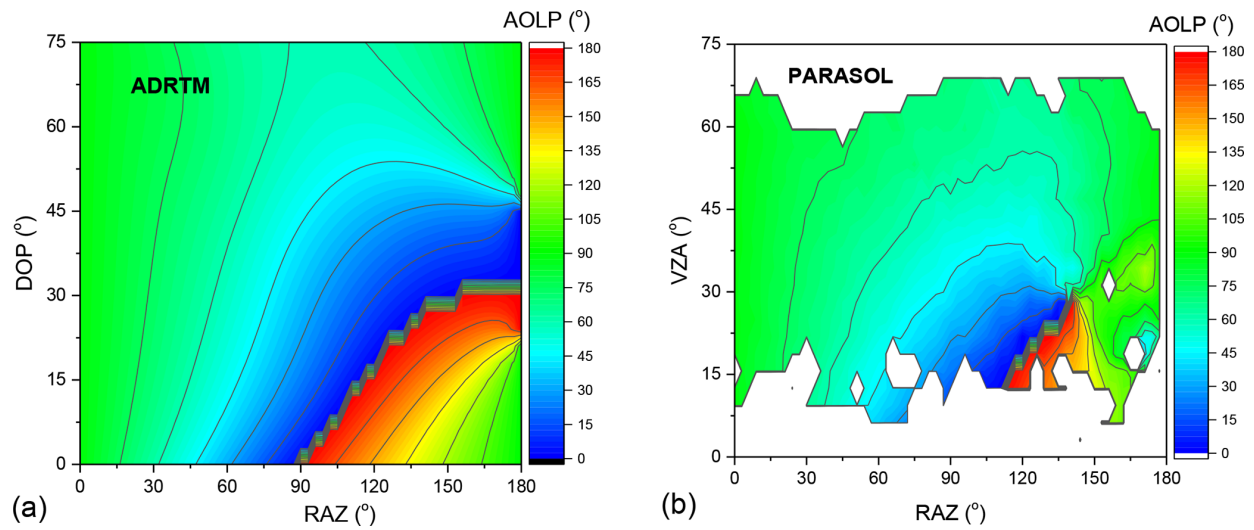

Figure 2. Same as in Fig. 1 but for the AOLP of the reflected light from the ADRTM $(\mathbf{a}, \mathrm{AOD}=0.3)$ and the PARASOL $(\mathbf{b}, \mathrm{AOD}=0.2-0.4)$.

dicates transparent cloud particles such as water droplets or ice crystals (Sun et al., 2014, 2015). This means the PARASOL OC2 aerosol product has cloud contamination. Thus, the aerosol properties in the PARASOL OC2 may not be very reliable for this case.

In summary, our modeling results show that the DOP of scattered sunlight can be used to detect aerosols. Figure 2 also shows that the AOLP of scattered light from nonspherical dust particles is very different from that of light scattered by clouds as reported in Sun et al. $(2014,2015)$. This can be used to differentiate aerosols from clouds, regardless of the ocean surface conditions. This is a simple and robust algorithm, which could be used to survey dust aerosols over midlatitude and tropical oceans, as planned by the NASA-Korea CubeSat mission for the detection of superthin clouds/aerosols.

Data availability. All data of this study are archived on the computer of NASA LaRC and can be obtained from the first author on request.

Author contributions. WS developed the method and conducted the modeling and data analysis. Other authors gave comments and suggestions and discussed requirements for the planned satellite mission on the dust detection based on this method.

Competing interests. The authors declare that they have no conflict of interest.

Acknowledgements. Wenbo Sun thanks Patricia Lucker of Science Systems and Applications, Inc (SSAI), for the management help during this work.
Financial support. This work was supported by NASA Langley Research Center's "Lidar Data Analysis and Theory" project.

Review statement. This paper was edited by Jianping Huang and reviewed by two anonymous referees.

\section{References}

Buriez, J. C., Vanbauce, C., Parol, F., Goloub, P., Herman, M., Bonnel, B., Fouquart, Y., Couvert, P., and Sèze, G.: Cloud detection and derivation of cloud properties from POLDER, Int. J. Remote Sens., 18, 2785-2813, 1997.

Deschamps, P. Y., Breon, F.-M., Leroy, M., Podaire, A., Bricaud, A., Buriez, J.-C., and Sèze, G.: The POLDER mission: Instrument characteristics and scientific objectives, IEEE T. Geosci. Remote, 32, 598-615, 1994.

Dubovik, O., Li, Z., Mishchenko, M. I., Tanré, D., Karol, Y., Bojkov, B., Cairns, B., Diner, D. J., Espinosa, W. R., Goloub, P., Gu, X., Hasekamp, O., Hong, J., Hou, W., Knobelspiesse, K. D., Landgraf, J., Li, L., Litvinov, P., Liu, Y., Lopatin, A., Marbach, T., Maring, H., Martins, V., Meijer, Y., Milinevsky, G., Mukai, S., Parol, F., Qiao, Y., Remer, L., Rietjens, J., Sano, I., Stammes, P., Stamnes, S., Sun, X., Tabary, P., Travis, L. D., Waquet, F., Xu, F., Yan, C., and Yin, D.: Polarimetric remote sensing of atmospheric aerosols: instruments, methodologies, results, and perspectives, J. Quant. Spectrosc. Ra., 224, 474-511, https://doi.org/10.1016/j.jqsrt.2018.11.024, 2019.

Herman, M., Deuze, J. L., Devaux, C., Goluob, P., Breon, F. M., and Tanre, D.: Remote sensing of aerosols over land surfaces including polarization measurements and application to polder measurements, J. Geophys. Res., 102, 17039-17050, 1997.

Kaufman, Y. J., Wald, A. E., Remer, L. A., Gao, B. C., Li, R. R., and Flynn, L.: The modis $2.1 \mu \mathrm{m}$ channel correlation with visible reflectances for use in remote sensing of aerosol, IEEE T. Geosci. Remote, 350, 1286-1298, 1997.

Sun, W. and Lukashin, C.: Modeling polarized solar radiation from the ocean-atmosphere system for CLARREO intercalibration applications, Atmos. Chem. Phys., 13, 10303-10324, https://doi.org/10.5194/acp-13-10303-2013, 2013. 
Sun, W., Videen, G., and Mishchenko, M. I.: Detecting super-thin clouds with polarized sunlight, Geophy. Res. Lett., 41, 688-693, https://doi.org/10.1002/2013GL058840, 2014.

Sun, W., Baize, R. R., Videen, G., Hu, Y., and Fu, Q.: A method to retrieve super-thin cloud optical depth over ocean background with polarized sunlight, Atmos. Chem. Phys., 15, 11909-11918, https://doi.org/10.5194/acp-15-11909-2015, 2015.

Tanré, D., Bréon, F. M., Deuzé, J. L., Dubovik, O., Ducos, F., François, P., Goloub, P., Herman, M., Lifermann, A., and Waquet, F.: Remote sensing of aerosols by using polarized, directional and spectral measurements within the A-Train: the PARASOL mission, Atmos. Meas. Tech., 4, 1383-1395, https://doi.org/10.5194/amt-4-1383-2011, 2011.

Zubko, E., Shkuratov, Y., Kiselev, N. N., and Videen, G.: DDA simulations of light scattering by small irregular particles with various structure, J. Quant. Spectrosc. Ra., 101, 416-434, 2006.
Zubko, E., Kimura, H., Shkuratov, Y., Muinonen, K., Yamamoto, T., Okamoto, H., and Videen, G.: Effect of absorption on light scattering by agglomerated debris particles, J. Quant. Spectrosc. Ra., 110, 1741-1749, 2009.

Zubko, E., Muinonen, K., Munoz, O., Nousiainen, T., Shkuratov, Y. Sun, W., and Videen, G.: Light scattering by feldspar particles: Comparison of model agglomerate debris particles with laboratory samples, J. Quant. Spectrosc. Ra., 131, 175-187, 2013. 